\title{
Dirty Pictures. Vulgar Street Art in Lahore, Pakistan
}

Jürgen Wasim Frembgen \& Asif Jehangir

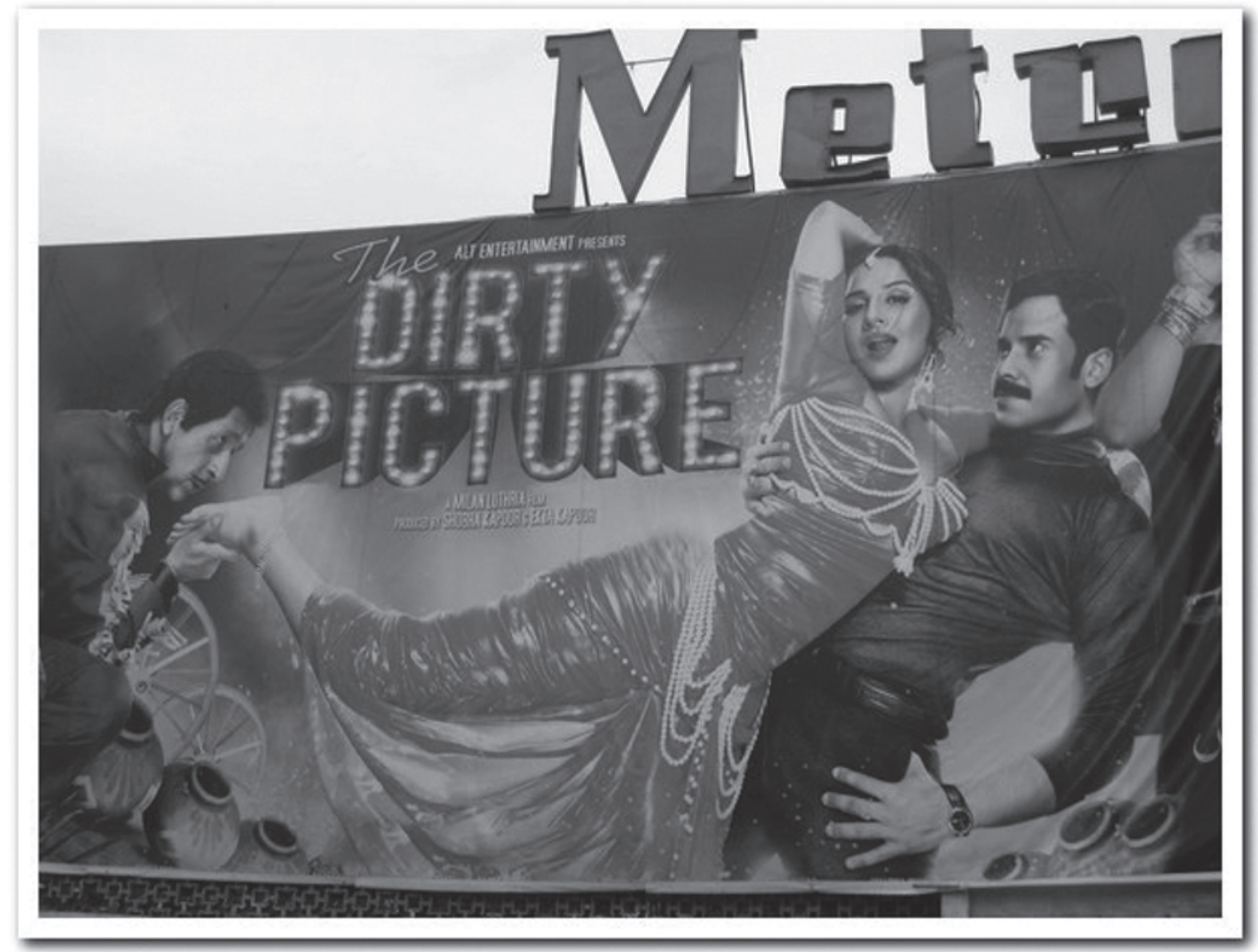

[FIG. 1]

Billboard advertising the

Bollywood movie Dirty

Picture, Metropole Cinema,

Abbot Road, Lahore 


\section{The dirty picture: spicy movies and offensive placards}

The title of this essay on a series of vulgarly designed film placards from the early $2 \mathrm{I}^{\text {st }}$ century is inspired by Milan Luthria's award-winning Bollywood movie The Dirty Picture (20II), an erotic biopic based on the tragic life of the South Indian actress Silk Smitha (Fig. I). Dubbed as the sex symbol of South Indian cinema, she struggled for money and fame, but had to count the costs through unrequited love, loneliness, and failed ambitions - not unlike Marilyn Monroe. Smitha ultimately committed suicide in 1996 at the age of 35 . In 2013, Silk - Sakkath Hot Maga, a Kannada version of The Dirty Picture with a similar plot, was released starring the Pakistani actress Veena Malik. Such »spicy, «masala« style movies focusing on romantic love, steamy, erotic dance numbers, lewd songs, rape scenes, crime, and violence are regularly shown in the traditional single-screen cinemas Lahore, Pakistan's cultural metropolis, on McLeod Road and Abbott Road. Stills and posters from The Dirty Picture and other commercial Hindi films, as well as from Punjabi and Urdu B-movies locally produced in Lollywood, Lahore's film industry, served as templates for the freehand-drawn placards that appeared in public spaces over the last one-and-a-half decades. They show »dirty scenes« with lascivious women engaged in sex and enticing poses with plenty of bosom exposed.

Such colorful images, considered »vulgar« (fahhashi) and »dirty« (ganda) not only in Pakistan, but also in other parts of South Asia and the Middle East, are depicted mainly on large billboards mounted on the facades of cinemas. ${ }^{1}$ From the 1930s, when the first cinema halls were built in Lahore, until the early $2 \mathrm{I}^{\mathrm{st}}$ century, these billboards were hand-painted by well-known masters. 
Ali Khan gives an overview of the development of this art from the heyday of the Pakistani film industry until today. ${ }^{2}$ These hand-painted billboards were gradually replaced by new digitally printed ones. In addition to these garish paintings and prints in huge format, large film posters and film stills in smaller format are commonly displayed in the anterooms and entrance halls of cinemas, which constitute an exclusively male environment. Frembgen saw the most obscene ones, advertising crudely produced films, at a small, old cinema called »Pakistan Talkies situated in the middle of Lahore's red-light district in Sheikhupura Bazaar inside Taksali Gate. Film posters are also displayed on the rear side of horse carriages and motor rickshaws and in this way are exposed around the city. The freehand-drawn images, however, which are the focus of this article, were found pasted boundary walls and facades across the city, often in the vicinity of cinema halls around Lakshmi Chowk, but also on Circular Road, Lahore's most congested and polluted ring road, close to the Walled City. Like most street art, they were temporary and torn or pasted over once their immediate usefulness in publicizing the film was expended.

Most of these bicolored images in smaller format are rather skillfully drawn and, albeit crude in content, appear charming in their own right. Hardly ever signed, they are apparently the work of streets artists commissioned by film distributors. As part of the rich, popular visual culture in public space, the film posters compete with other placards and banners, such as portraits of politicians during election campaigns, announcements of political rallies, and invitations to religious gatherings, pilgrimages, wrestling tournaments, and other sports events, etc., as well as the omnipresent, huge commercial billboards. Thus far, they have remained unoticed by researchers. ${ }^{3}$ Below, we 
first look at their taboo iconography and then into the moral discourse related to their undoubted efficacy in attracting the male gaze.

\section{The lure: fleshy female bodies}

Unlike the cinema billboards with their characteristic mix of male and female bodies, featuring bearded macho villains wielding weapons juxtaposed with tender heroines or vamps, our images in freehand drawing show a clear focus on the female, whereby the male figure recedes into the background or is completely absent. The painter thus accentuates female body contours with voluptuous forms, swelling breasts and hips, emphasizing their buttocks; the women's figures are rarely slender and barely clothed in filmy garments, often with plunging necklines or bras. Their hair is uncovered and flowing; their full lips are at times open in a sensuous expression. The poses in which the actresses are depicted are either vulnerable to male brutality, longing (for instance with arms crossed behind the head), sexually arousing, or proud, forceful, and menacing. Thus, the range of body forms and poses is rather wide, whereby the female body is always displayed as a spectacle. Below we take a closer look at the images.

Fig. 2 shows a scene from Guddu Badsbab, a typical vengeance-themed Punjabi film released in 2004 in which male brutality is glorified and women are humiliated. The actress Saima, wearing jingling ankle bells, the sign of a professional dancer, lies fearfully on the ground awaiting a violent attack, her buttocks sensuously exposed; the actor Shaan menacingly holds a dagger. In 
fact, Saima Noor was the leading heroine of many Punjabi and Urdu films produced in Lahore throughout the 1990 s and 2000s. This drawing, with its well-accentuated body proportions, almost conveys the effect of a woodcut.

The placard from the film Kbuni Misban (Bloody Mission) is a naturalistic drawing in which space is divided by a diagonal accentuated by a Kalashnikov: the busts of two young women are shown in the larger upper triangle, whereas the smaller lower triangle is filled with Urdu text (Fig. 3). A translation of the latter reads: »To end the reign of the lords of crime and terror, the world's loveliest, most subtle and cunning beauties have been chosen who, with their amazing coquetry and the fire of the ammo in their breasts, destroyed the empire of crime! « This explains well the drawing's emphasis on the ladies' cleavages and their provocative looks. In this way, female bodies complement the archetype of the male hero, who indulges in extreme violence.

Fig. 4 is a placard from the Punjabi movie Bbola Sajan (Simpleton Beloved!, 2004) with a loving couple in the upper part, showing a fleshy female fondly leaning over a mustachioed male, and two younger, buxom women in the lower part. The one on the right shown in profile exposes her armpit in a challenging pose. Here it should be pointed out that, according to conservative Islamic morality, sleeveless shirts are generally considered indecent and the exposure of the armpit particularly shameful. Thus, in Pakistani body topography, the armpit, with its dark, hairy cavity, is considered such an intimate part of the body that it is homologically related to the female genitals. Moreover, this can be associated with memories of body odor, especially foul-smelling ones, which is again symbolically associated with animalistic sexual appetite. ${ }^{4}$ The figure on the left shows another well-known actress with her uncovered 


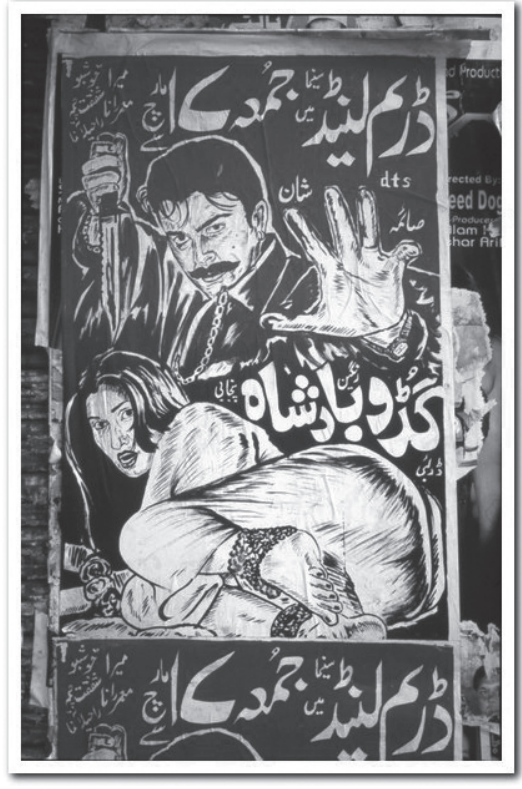

[FIG. 2]

[FIG. 2]

Scene from the violence-

ridden film Guddu Badsbab,

placard, Lahore

[FIG. 3]

Women with gun from the film Bloody Mission, placard, Lahore

[FIG. 4]

Three females with a simpleton from the film Bbola Sajan,

placard, Lahore

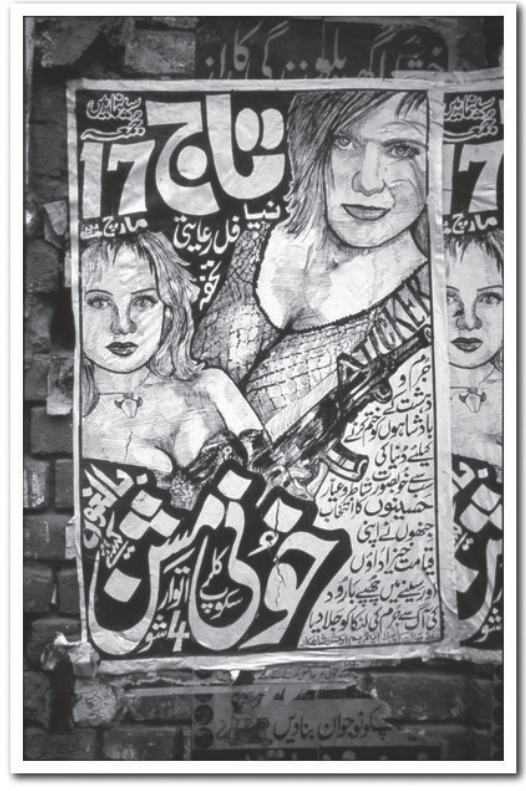

[FIG. 3]

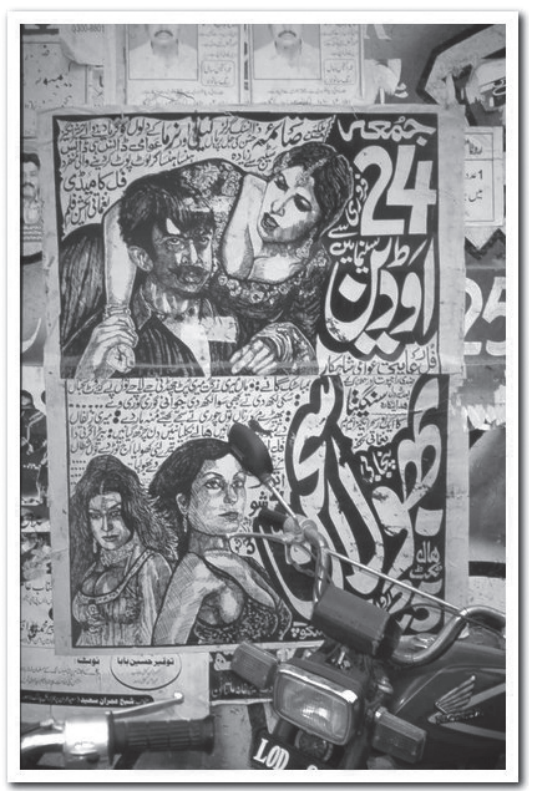

[FIG. 4] 
wild tresses and her breasts almost spilling out of her low-cut dress, with plenty of cleavage on display.

Apart from their forms and postures, the figures on this placard are surrounded by texts that refer to vulgar, richly double-entendre Punjabi lyrics from songs in the movie itself. These songs are described on the poster as being »bombastic« and feature suggestive lyrics such as, »bad men, in secret from their wives, chase after girls left and right! «s In comparison with the previously discussed placards, Fig. $\zeta$ is simpler, but charmingly and delicately drawn. In the upper part, it shows a loving couple reclining on a bench, the woman fleshy, corresponding to Punjabi ideals of beauty, and the man in typical rural Punjabi dress with a loincloth. In the lower part, the couple is lying on the floor ready to make love, the woman already semi-nude with a suggestively raised leg, the man on top of her. This placard is a cinema advertisement for the Punjabi action movie Bala Badmash (2007). »Badmash« means scoundrel, and $B \mathrm{Bala}$ is a shortened form of »Iqbal«; such shortening of personal names into nicknames is common in Punjab.

Fig. 6 shows a single female dancer with her bare arms raised above her head. The placard's tag lines for the Urdu film Raqasa (The Dancer), released in 2002, say: »A film that teaches a lesson« and »a priceless gift for women.» Apparently, in terms of content, the film intends to teach women a moral lesson. The drawing is rather well executed. In addition, the inscriptions take up the rhythm of the dance movements, because the film title is repeated four times and accompanied by the exclamations »dhoom machane-wali filum « (a film that created an uproar! $)^{6}$ and »super-hit filum (which is self-explanatory).

Placards for other movies in the same melodramatic and/or action genre, like Jism (Body, 2006), Anaconda 2 (dubbed in Hindi in 2004), and Murder (2006) 


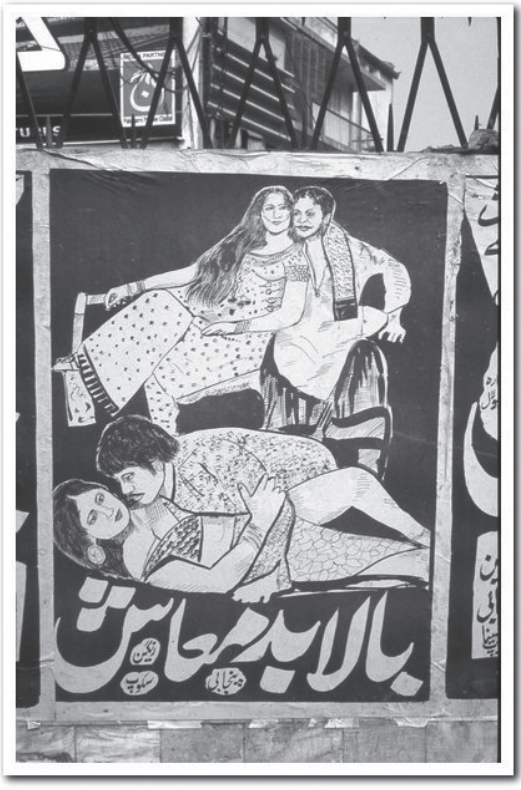

[FIG. 5]

Placard advertising a typical

Punjabi action movie, Lahore

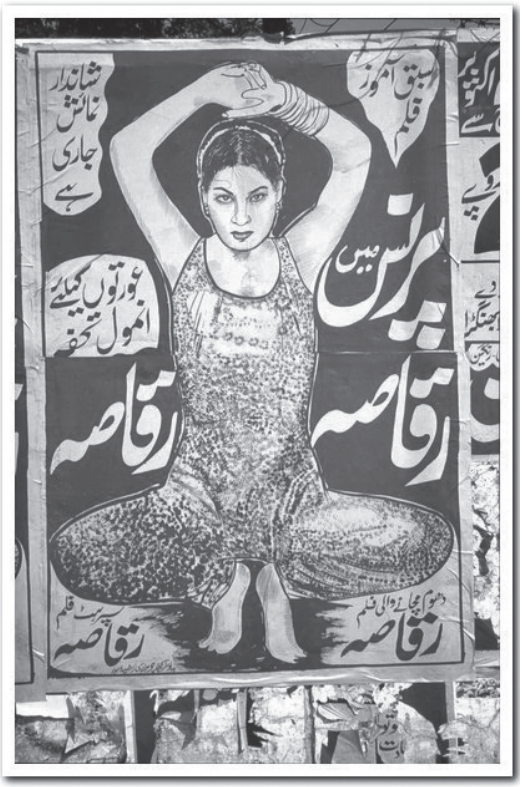

[FIG. 6]

Female dancer, placard,

Lahore

likewise show women in bikinis, with »thunder thighs«, in enticing and inviting poses, trayed as avenging angels or as vamps steeped in sin and flaunting their bodies. In general, images of scantily clad women are presented as over powering, sexualized figures meant to appeal to the basic instincts of male onlookers. As such, they »galvanize « the collective fantasies, especially those of provincial males. This imagery of »spicy« movies, common since the r 980 s and 1990s, shows a stereotype of femaleness crudely reduced to its sexuality, which is considered dangerous and disruptive. 


\section{The response: from toleration to mutilation and disappearance}

The eye-catching images of fleshy and lascivious women discussed above are meant to stimulate male desire and to entice them to watch the crime and action movies in cinemas. Taking into account that public space in Lahore and other cities of Pakistan is a male sphere under Islamic gender segregation and that film screenings are well attended, these images prove to be very efficient. As could be observed in Lahore, men sometimes contemplate the depicted female bodies on billboards, posters, and placards for a long time, or at least they notice them with a sidelong glance while walking on the road. Farida Batool has pointed out that »scopophilia«, using Freud's term for the sexual pleasure of looking at naked bodies, is a basic characteristic of the general male psyche, especially in urban Pakistan. ${ }^{7}$ While men often take visual delight in gazing at these images, conservative Muslims consider them indecent, vulgar, and obscene; see, for instance, the still of the film Gunab ki basti (Quarter of Sin) (Fig. 7).

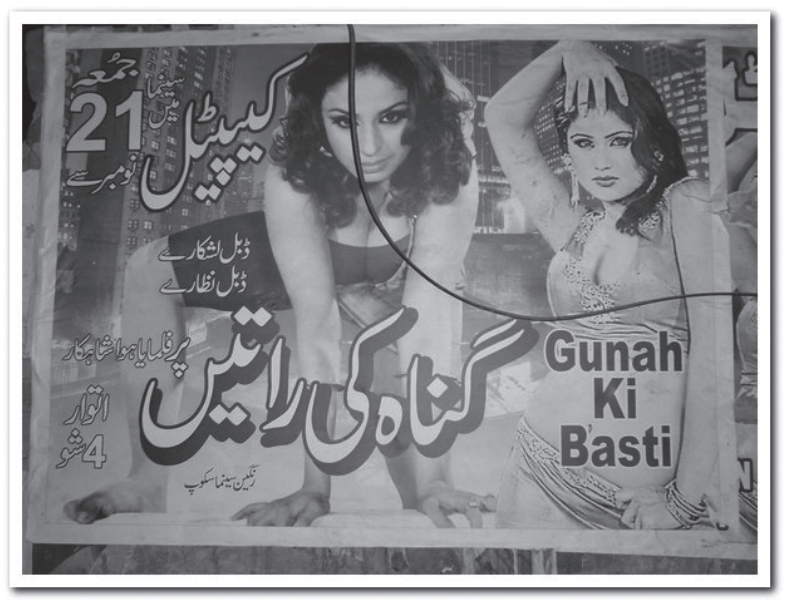

[FIG. 7]

Poster advertising the film Quarter of Sin, (Gunabon Ki Basti, while the Urdu script gives the film title Gunab Ki Raatein which means Nights of Sin). Pakistan Talkies Cinema, Lahore 
Remarkably, at least until the late 2000 s, there has been a certain sense of toleration of the presence of these images in public. Despite growing Islamic orthodoxy and the rise of radical Islamist movements that emphasize strict morals, there were hardly any calls to remove these »inappropriate « representations of the female form. This is all the more surprising, considering how the attempt was made to enforce »Islamic society« during the military rule of General Zia ul-Haq (1977 - 1988); and it shows a certain persistence of secular visual culture in Pakistan. The Pakistani Film Censorship Code from 1979 section IV deals with »immorality and obscenity « and clearly states that a movie will be deemed unsuitable for screening if it »contains dialogues, songs, speeches, dances, jokes, or gestures which are obviously vulgar, obscene or indecent. « ${ }^{8}$ The same holds true if it »displays dances showing indecent or vulgar movements or passions « (section VI) or »glorifies vice, crime, violence $[. .$.$] 《 (section VII). If the strict rules$ of this code were to be implemented in its full spirit and letter, then such »spicy« movies could hardly be shown. However, as the chairman of the Lahore censor ship board commented about the screening of these soft-porn films by distributors: »They show unauthorized scenes in the cinema halls, which had been deleted by the board, in connivance with cinema owners and sometimes even our own functionaries at some level. « ${ }^{9}$ In her discussion of works of Pakistani popular art and elite »high art, «Batool explains that whereas some of the latter became the target of zealots who considered them offensive and threatening to Islamic ideology, popular representations remained untouched. ${ }^{\text {Io }}$ She argues that these images that invigorate sexual desires among larger male audiences remained out of the reach of zealots because the status of their painters was much lower than that of contemporary artists belonging to the elite. Thus, Batool wrote: 
Hence, cinema board painters are allowed to keep on producing cinema paintings, as they do not contradict the underlying assumptions and political agenda that the »designed « cultural identity of Pakistan is expected to serve $[. .$.$] . On the other hand, allowance of cinema paintings$ further enforces the image of women as the embodiment of sexual desires that need to be tempered and controlled in order to »reform « society. ${ }^{\text {II }}$

Here it should be emphasized that cinema billboard painting was almost extinctin 2006 when Frembgen documented the work of the last painters in Lahore, Karachi, and Rawalpindi. ${ }^{12}$ As mentioned above, such paintings were replaced by digital prints, which are aesthetically less charming than the hand-painted ones.

In addition, Batool points to the gender discourse as another important aspect that may explain the degree of tolerance shown toward cinema billboards. She notes:

The motivation behind these fleshy and sensuous images is the belief that these film actresses belonged to the red light area of the city and, thus, are available and subject to male desires. The presentation of women belonging to the »public « sphere is common property and the need to codify women as safeguards for the national culture is only limited to respectable women. It is strange that no significant protest has been recorded on the representation of these women even by fundamentalist groups, since it does not seem to equate to a disfiguring of women's dignity. ${ }^{13}$ 
The seducing actress, the »bad woman« so to speak, is thus portrayed as the exact antithesis of the »wife, " the "good woman, " meaning the moral touchstone of the family as obedient daughter or caring mother. ${ }^{14}$ This is corroborated by the statement of a film director from Lahore who said: "prostitute ko sharif bibi to nahin dekha-sakte. "(We can't portray a prostitute as a woman of virtue). ${ }^{\text {I5 }}$ While we agree with the analysis Batool presented in 2004, we also need to emphasize our observation that in recent years in Lahore a number of cinema billboards as well as juicy film posters and placards were either scribbled or painted over or destroyed. The same transition from relative toleration to mutilation and destruction happened in Karachi and particularly in Peshawar, the stronghold of Taliban and other Islamist activists. Likewise, international publications distributed in Pakistan, especially fashion magazines, are regularly censored; and »sexually explicit « and »offensive« images are »defaced « using black markers. ${ }^{16}$ Similarly, access to certain websites is sometimes blocked.

Thus the wind changed after 9/I and since the mid-2000s as far as the display of crude, sexually loaded pictures in public is concerned. They unleashed the passions of radical Islamists, who burned down cinemas in their zeal to eradicate all that they considered »un-Islamic.« Shoaib Mansoor’s film Kbuda ke liye ${ }^{17}$ for example, vividly depicts this in an early scene that shows religious fanatics burning down and destroying cinema billboards. In conservative scriptural Islam, the human body is considered $"[.$.$] a source of shame and there-$ fore it should be concealed and covered, $\ll^{18}$ and painting or drawing the body is frowned upon. Incited by hate preachers, activists were encouraged to take action against what they considered sinful and prohibited according to Islamic law. Muslim moralists see it as their duty to command »right« and forbid »wrong.« 


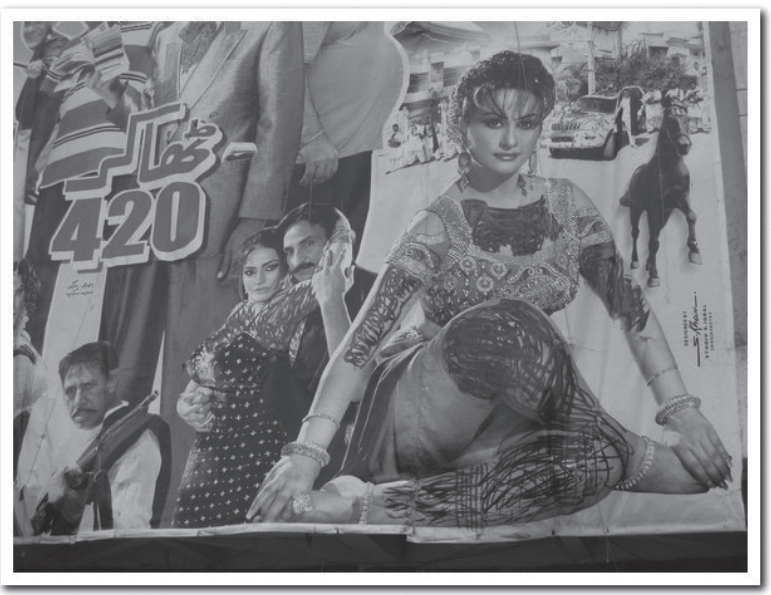

[FIG. 8]

Blackened female bodies on a poster advertising the Punjabi film Taksi 420 , Lahore

In modern times, going to the cinema, "posters advertising dirty films, cafés, playing-cards, and music on the radio and television « ${ }^{19}$ have been added to the slew of wrongs condemned by conservative religious scholars. Without entering deeper into the internal debate among zealous Muslims over the duty to stop wrongdoing, a key issue of normative Islam, we note that, in the context of Pakistani media of film promotion, these activists imposed their own standards of virtue on their co-religionists by blackening, disfiguring, or tearing down images of the faces and bodies of women on cinema billboards to create what they consider an »Islamic « moral aura. This response can be aptly described as an »affective raptus, « to use Horst Bredekamp's expression..$^{20}$ Vivid examples are the movie stills on display at the cinema »Pakistan Talkies « in Lahore's red-light district, in which naked parts of the female body are crosshatched and thereby blackened (Fig. 8). Alongside these iconoclastic actions, there is a new conser- 
vative religious trend to exhibit piety in public through Islamic dress, especially veiling, and to attend prayers in the mosque. Actresses like Saima Noor emphasize that they say their five daily prayers.

Today, Photoshop-generated, digitally printed cinema billboards are no longer as prominently displayed in public spaces as the banners seen in the photographs in Batool's book; as far as their attractiveness is concerned, these new large rectangular billboards lack the vividness and exuberant imagery of their hand-painted predecessors, which often also stood out because of their irregular formats following body contours. Unlike cinema billboards and film posters, ${ }^{21}$ the charming placards drawn freehand that we depict in our essay, which constituted a veritable street art, have disappeared; at least we could not find them any more since 20 II.

\section{Conclusion}

»Dirty Pictures, "such as our film placards that are obsessed with women's bodies, are emotionally charged and instigate responses. Both the sensuous indulgence in them and their mutilation, destruction and finally disappearance come across as an expression of Pakistani hyper-masculinity. In the imagery of these placards, either the testosterone-driven male uses and castigates the female or the woman is portrayed as seductress or avenging angel. Finally, man remains the conquering hero - like the passionate zealot enthralled by the Islamist agenda who feels »offended « by these images and eradicates the »wrong « and $» \operatorname{sinful} . \ll^{22} \mathrm{Be}$ it the pleasure-seeker and cinema-goer or the Islamist iconoclast, 
we agree with Durre Ahmed's statement about the current social context in Pakistan: »Secularor religious, the brutalizing and obliteration of the feminine is all-pervasive. ${ }^{23}$

The sexually loaded images discussed in this paper are generally considered »obscene, « »ulgar, « and »dirty.« Whereas male aggression and violence are tolerated, nudity, especially of women, is held in abhorrence, considered dishonorable, immodest, and representing the dissolution of the normatively highanchored bonds of shame. ${ }^{24}$ At least since the Islamist regime of $\mathrm{Zia}$ ul-Haq (1977 - 1988) with its repressive wave against »un-Islamic« behavior, times have changed; there is public demand for stricter morality. ${ }^{25}$ Many people are now hypersensitive to such images and feel offended by being exposed to them. The placards called »dirty pictures« are increasingly perceived as »offensive« not only by the self-proclaimed custodians of morality, but also by the wider public as insulting the religious feelings of the majority of mainstream conservative Muslims in Pakistan, who say they should be erased from public view. This attitude toward these images reflects the increasing influence of a distinctly conservative and rigid interpretation of Islam with a puritanical outlook. Although in recent years these freehand-drawn placards, which were typical features of Lahore's street culture, have vanished as media of film publicity, much like old hand-painted billboards with their peculiar aesthetic, their offensive character persists to some extent in the new »realistic « film banners and especially in the movie stills on display in cinemas situated in the city's redlight districts. Vulgarly displayed images of the female body thus remain the projections of popular male sexual fantasies and desires. ${ }^{26}$ 
1 Cf. Jürgen Wasim Frembgen: The Sacred and the Vulgar. Sufi Posters and Cinema Billboards from Pakistan, in Norbert M. Schmitz (ed.): Ästhetik der Globalisierung, Nuremberg (in press).

2 Ali Khan: Pakistani Film Poster Art, in Bioscope. South Asian Screen Studies 5/2 (2014), Pp. 183-190.

3 We know of only one such picture in Farida Batool: Figure. The Popular and the Political in Pakistan, Lahore 2004, plate 33 , which shows multiple layers of multicolored and bicolored placards pasted on a wall in Lahore.

4 Cf. Harward Malchow: Gothic Images of Race in Nineteenth Century Britain, Stanford 1996, p. I4I.

5 The literal meaning of the song is, »Bad men, in secret from their wives, shove their mouths in, left and right. «This evokes not only animals feeding at a trough, but, obviously, also cunnilingus.

6 Due to its success (in this context).

7 Batool: Figure (see note 3), p. 55 .

8 Amber Rahim Shamsi: Much Rain and Mangoes, in The Herald (Karachi) 32/9 (200I), Pp. II9-I20.

9 Ibid., p. 120.

${ }^{10}$ Batool: Figure (see note 3), pp. 56-57.

11 Ibid., p. 52.

${ }^{12}$ Frembgen: The Sacred and the Vulgar(see note r).

13 Batool: Figure (see note 3), pp. 57-58.
${ }^{14}$ Cf. Afiya Shehrbano Zia: Sex Crime in the Islamic Context. Rape, Class and Gender in Pakistan, Lahore 1994, P. 43.

15 Amber Rahim Shamsi (see note 8), p. I2I.

16 Sanam Maher: Making a Mark, in The Herald (Karachi), December issue (2011), pp. 56-58.

17 Pascal Zinck: Blind Faith. Women at War in Khuda kay liye and Escape from Taliban, in Pakistaniaat. A Journal of Pakistan Studies 4/2 (2012), Pp. I23-140.

${ }^{18}$ Fuad I. Khuri: The Body in Islamic Culture, London 2001 , p. 35 .

${ }^{19}$ Michael Cook: Forbidding Wrong in Islam, Cambridge 2003 , p. II6.

${ }^{20}$ Horst Bredekamp: Theorie des Bildakts, Berlin 2010.

${ }^{21}$ Cf. Rajesh Devraj / Paul Duncan (eds.): The Art of Bollywood, Cologne 2010 .

${ }^{22}$ Cf. Durre S. Ahmed: Heroes and Zeroes, in Saima Zaidi (ed.): Mazaar, Bazaar. Design and Visual Culture in Pakistan, Karachi 2009, pp. 97-103, here p. 98.

23 Ibid, p. 99

${ }^{24}$ Cf. Jürgen Wasim Frembgen: Tying and Untying the TrouserCord: Dimensions of Normativity, Morality, and Emotion in Pakistani Body Behaviour, in The Asia Pacific Journal of Anthropology 5/r (2004), pp. 49-70, here pp. 58, 62, 64.

${ }^{25}$ Cf. Khawar Mumtaz / Farida Shaheed: Women of Pakistan. Two Steps Forward, One Step Back?, Lahore 1987. Thus, in a chapter on »obscenity« the authors emphasize: »In May 1982 the government launched a campaign against 
obscenity and pornography. While there is no doubt that the problem of obscenity is valid in itself, the issue as defined by the government seemed to equate women per se with obscenity;« (p. 8r). In consequence, women were eliminated from product advertising, newspapers reduced the number of photographs showing women, and film editions were stopped altogether. Female visibility became equated with obscenity (p. 8).

${ }^{26}$ Batool: Figure (see note 3 ), p. 78 . 